\title{
COREOGRAFIAS DIDÁTICAS: REFLEXÕES ACERCA DOS ENCAMINHAMENTOS DOCENTES EM SALA DE AULA PARA O ENSINO- APRENDIZAGEM NAS ARTES VISUAIS ${ }^{1}$.
}

\author{
COREOGRAFÍAS DIDÁCTICAS: REFLEXIONES SOBRE LOS \\ PROCEDIMIENTOS DOCENTES EN SALA DE CLASE PARA LA ENSEÑANZA- \\ APRENDIZAJE EN LAS ARTES VISUALES
}

\section{TEACHING CHOREOGRAPHIES: REFLECTIONS ABOUT THE TEACHERS' DIRECTION IN THE CLASSROOM TO TEACHING-LEARNING IN VISUAL ARTS.}

\author{
Vivian Castro de MIRANDA ${ }^{2}$ \\ Adriana Moreira da Rocha VEIGA ${ }^{3}$
}

RESUMO: Este texto tem como tema a reflexão sobre as estratégias didáticas na perspectiva das chamadas "coreografias didáticas", resultantes dos procedimentos empregados em sala de aula. O objetivo é refletir sobre os encaminhamentos docentes, no recorte da pedagogia universitária. A problemática leva a questionar os aspectos que envolvem as decisões docentes enquanto dinamizadoras do processo de ensinoaprendizagem. Através de levantamento bibliográfico e observação em sala de aula, a conclusão é de que do ponto de vista do estudante, as coreografias propostas pelos professores têm um real impacto na forma como se dá o aprendizado.

PALAVRAS-CHAVE: Coreografia didática. Estratégia didática. Ensinoaprendizagem. Ideias pedagógicas. Artes visuais.

RESUMEN: Este texto tiene como tema la reflexión sobre las estrategias didácticas en la perspectiva de las denominadas "coreografías didácticas", resultantes de los procedimientos empleados en sala de clase. El objetivo es reflexionar sobre los procedimientos docentes, en el ámbito de la pedagogía universitaria. La problemática nos hace cuestionar los aspectos que involucran las decisiones docentes en cuanto dinamizadoras del proceso de enseñanza-aprendizaje. Por medio del análisis bibliográfico y observación en sala de clase, la conclusión es de que la perspectiva del estudiante, las coreografías propuestas por los profesores tienen un real impacto en la forma como se da el aprendizaje.

PALABRAS CLAVE: Coreografía didáctica. Estrategia didáctica. Enseñanzaaprendizaje. Ideas pedagógicas. Artes visuales.

\footnotetext{
${ }^{1}$ Texto produzido para a disciplina de "Docência Superior" do Programa Especial de Formação de Professores para a Educação Profissional.

${ }^{2}$ Mestre em Comunicação Midiática pela UFSM - Universidade Federal de Santa Maria, Santa Maria RS - e-mail: vicacastro@gmail.com.

${ }^{3}$ Doutora em Educação. Professora Adjunta na UFSM - Universidade Federal de Santa Maria Departamento de Fundamentos da Educação. Coordenadora do Programa de Pós-Graduação em Educação - e-mail: adriana.macielrm@gmail.com
} 
ABSTRACT: The topic for this text is the reflection about the teaching strategies in a perspective called "teaching choreographies", which is a result of procedures performed in the classroom. The purpose is to reflect about the teaching direction, based on the university pedagogy. The problematic issue takes to questionable aspects which involve the teaching decisions as motivators for the teaching-learning process. By means of bibliographic surveys and classroom observation, the conclusion is that, from the student's point of view, the choreographies proposed by the teachers have a real impact in the way learning takes place.

KEYWORDS: Teaching choreography. Teaching strategy. Teaching-learning. Pedagogical ideas. Visual Arts.

\section{Primeiras palavras}

Esse texto foi produzido em um contexto particular de reflexões sobre a docência superior, especialmente inspirado na especificidade deste âmbito de ensino e de seus desafios no que tange ao aspecto do ensino-aprendizagem. Ocorre que para que se possa repensar algo é necessário compreendê-lo. Dizendo de outro modo, é preciso indagar sobre, por exemplo, como se organiza o trabalho pedagógico, como faz Maciel (2010), ou sobre como se constitui o processo pedagógico como um todo, e assim por diante.

De tal modo, o que se percebe é uma real necessidade de pensar os processos que se dão em sala de aula, e do ponto de vista do professor, trazer a possibilidade não somente de um posicionamento coerente com aquilo que é por ele proposto, como ao mesmo tempo saber-se inserido em um processo de qualidade, apesar de este termo ser um tanto polissêmico.

O que se quer afirmar é que, na contemporaneidade, após uma história das ideias pedagógicas construídas, é preciso lançar um olhar para o que efetivamente está sendo feito em sala de aula, e compreender acima de tudo esse processo dentro de alguma perspectiva, que leva ao que se vêm chamando nos estudos sobre a docência e o ensino de "coreografia didática".

Esta metáfora, a que muitos estudiosos estão se referindo na atualidade, diz respeito justamente à compreensão de que os encaminhamentos docentes apontam para uma configuração tal que fazem representar a encenação de uma coreografia, que envolve ele mesmo (o professor) e o estudante, portanto, o ensino e a aprendizagem. $\mathrm{Na}$ 
pedagogia universitária, este tema tem sido recorrente devido às especificidades do público e ao estilo de ensino, que deve estar amparado em abordagem crítico-reflexiva.

\section{Lugares da cena educativa: "coreógrafos" e "atores"}

Quando se fala na cena da sala de aula, surge em mente a situação ideal de professores e estudantes em busca de um fim comum: a aprendizagem. É nesse sentido que as reflexões sobre a didática empregada se encaminham, procurando dar conta de quais os aspectos pertinentes aos encaminhamentos docentes, o que é significativo para o aluno em termos de atitudes que desenvolvam sua vontade e efetiva aprendizagem.

No recorte específico das aprendizagens proporcionadas pelos docentes é que se insere a noção de "coreografias didáticas", na medida em que o professor torna-se responsável pelo contexto de aprendizagem dos alunos, pois coreografias diversas (estratégias de ensino) podem ser postas em prática para orientá-los (ZABALZA, 2006 apud MACIEL, 2010).

O professor como "coreógrafo" é uma visão que põe sobre os ombros deste profissional a tarefa de "ensaiar" com os alunos o processo da aprendizagem, e isto demanda que sejam colocadas em prática suas habilidades pedagógicas e os conhecimentos específicos de sua área (Maciel, 2010), além da sua subjetividade, que aponta, por exemplo, para o seu grau de motivação.

No que se refere ao item "habilidades pedagógicas", é possível compreender neste uma série de procedimentos e ideologias relativas ao trabalho docente que fazem com que cada professor seja um coreógrafo distinto. Com base em Maciel (2010), citamos alguns aspectos referentes a este âmbito da profissionalidade docente: (i) proposta pedagógica pertinente, (ii) estratégia de ensino compatível, (iii) articulação dos procedimentos de ensino com a proposta e a estratégia adotada, (iv) implicação no processo de ensino-aprendizagem, entre outros.

O que se vê é que todos estes aspectos das habilidades docentes fazem valer uma perspectiva pedagógica sobre a qual se alicerça todo o trabalho. Embora seja algo difícil de ser analisado de uma forma isolada, pois a própria instituição de ensino, bem como cada área pressionam para certos caminhos a serem seguidos, é inevitável não trazer à luz para qual perspectiva o docente aponta. Esta perspectiva tem um impacto real sobre os encaminhamentos docentes, suas atitudes e procedimentos adotados, e para a aprendizagem. 
Enquanto estudante é bastante fácil criticar a "pedagogia" do professor, mas por outro lado é muito difícil se perguntar sobre que tipo de coreógrafo eu quero ser como professor? Não somente porque é preciso tomar decisões acerca de todos os aspectos antes colocados, bem como posicionar-se diante do contexto encontrado - eu posso ser este tipo de coreógrafo no horizonte das TIC's?

Por mais difícil que possa parecer posicionar-se a partir do âmbito pessoal, mais complicado ainda é saber que as circunstâncias atuais levam o professor a adequar-se às demandas, que muitas vezes desarticulam sua pretensa coerência construída ao longo do tempo. A busca por qualidade no ensino obriga a todo o momento para adequações, e isto implica rever propostas, procedimentos, etc. E sendo que as ideias pedagógicas também mudam através do tempo, sempre haverá a questão de que tipo de coreógrafo eи quero/posso ser?

Gadotti (1995), ao se referir à pedagogia, remete à história das ideias pedagógicas relacionadas ao pensamento sobre educação e às formas de ensinar. $\mathrm{O}$ autor chama a atenção de que na verdade existem muitas concepções pedagógicas, que existiram ou que coexistem através dos tempos: tecnicista, libertadora, construtivista, etc.

\section{A coreografia}

Segundo os estudos recentes sobre pedagogia universitária, aquilo que o professor leva o estudante a fazer, devido à implementação das estratégias didáticas que ele utiliza, tem um consequente impacto na sua aprendizagem.

Em relação a isso, Zabalza (2006 apud Padilha et.al) chama a atenção para as "coreografias" de que os professores lançam mão para a realização de sua atividade de ensino. Rios (2008:76) também lembra que é da prática do ensino que decorre a aprendizagem, pois a autora se questiona sobre "o que nós fazemos com eles e o que eles fazem conosco?”. Está procurando dar continuidade ao pensamento de que na verdade "fazemos a aula juntos", ensinamos e aprendemos, vivenciamos experiências.

A partir destas considerações, o que se pretende é fazer uma aproximação com a ideia de que um não existe sem o outro, e mesmo que não se possa afirmar sobre a aprendizagem, esta é buscada em toda a situação de ensino. Assim, é possível dizer que na Universidade como lugar de ensinar e aprender, não são somente os conhecimentos 
estão em jogo, mas a consciência do grupo, pois os protagonistas da cena devem estar envolvidos de tal maneira que cada um cumpra com o seu papel.

Rios (2008), contudo, alerta-nos que é preciso tomar cuidado com a afirmativa de que quando "fazemos" aula também ensinamos, pois a perspectiva da aprendizagem coloca o problema do outro, e também do que é feito em sala de aula e fora dela, dos contratos que são estabelecidos entre os sujeitos, ou seja, trata-se de um processo bem mais complexo.

A tradicional parte do professor neste processo, uma vez tomado seu posicionamento que é bastante pessoal sobre qual modelo de ensino a utilizar, determina que a partir daí, para tornar possível a implementação de seus planos, deve buscar meios para isso. Na prática, segundo a literatura, o que torna isto possível, dentre outras coisas, são as estratégias didáticas postas em cena, compondo uma coreografia.

A fim de compreender uma coreografia didática, Padilha et.al buscaram explicitar o que contempla esta proposta com interesse na educação online, apresentando a seguinte estrutura: (i) antecipação, (ii) encenação, (iii) modelagem da aprendizagem e (iv) aprendizagem como produto. Estes itens compreendem (i) o levantamento das aprendizagens e o planejamento das atividades de ensino, (ii) as ações relativas ao que foi proposto no pensamento, (iii) previsão da sequência cognitiva e prática do educando, (iv) resultado previsto da sequência cognitiva e prática do educando.

Uma estratégia didática, resumidamente, é a forma que docentes e alunos têm de se envolver de modo estratégico em torno de um objetivo comum que é ensinar e aprender, além de dar visibilidade ao processo. $\mathrm{O}$ mais importante, dentre as reflexões que são feitas em torno desta questão, como, por exemplo, se a estratégia é ou não adequada ao plano de ensino, aos conteúdos, aos objetivos, enfim, é questionar se aquilo que está sendo proposto não significa uma "coreografia pobre", minimalista, sem impacto para a aprendizagem. Isto envolve uma reflexão que vai além de "um" modelo de ensino a que o professor se filie, e traz a problemática da flexibilidade e do avanço sobre a didática empregada na Universidade.

\section{Observação de contexto áulico: a disciplina "ateliê de serigrafia"}

Conforme o que foi dito no item 1 desse texto, as reflexões aqui contidas sobre a docência superior têm o objetivo de pensar este âmbito de ensino e de seus desafios no 
que tange ao aspecto do ensino-aprendizagem. Para tal, foram feitas observações em sala de aula, no curso de Artes Visuais da UFSM/RS, como requisito para o cumprimento de atividades curriculares da autora deste trabalho. Este processo teve grande importância, uma vez que criou a possibilidade de rever na prática os rebatimentos da teoria, sobretudo sobre a questão didática, que envolve atores num cenário complexo.

A disciplina "Ateliê de Serigrafia", ministrada pela Professora Lusa Aquistapasse $^{4}$, proporcionou a reflexão de questões específicas que dizem respeito ao ensino nas áreas visuais, o que motivou a escolha de tal disciplina para fins de observação. Desde o início, o que se percebeu foi a necessidade de adaptação do conhecimento pedagógico aos contextos, ou seja, é na observação que nos damos conta de que é necessário buscar a atualização das estratégias de ensino-aprendizagem para as respectivas áreas de ensino. Assim, o que é válido para algumas áreas, nem sempre se faz possível na prática de outras.

Chamou a atenção, dentre os vários aspectos da "pauta de indicadores de observação de ambiente áulico" 0 aspecto das "condutas docentes", fazendo pensar que em campos de ensino como o das áreas visuais o professor deve estar preparado para adaptar-se às situações que forem aparecendo, ou seja, um roteiro didático pronto nem sempre pode ser colocado em prática na sua íntegra, visto que são de diversas ordens as demandas dos alunos em disciplinas de caráter criativo. Como nem todos os discentes se encontram em uma mesma etapa com as suas atividades, muitos necessitam de atendimento diferenciado, seja por questões técnicas advindas da linguagem da serigrafia, seja por questões estéticas, porque precisam tomar decisões acerca dos rumos do próprio trabalho.

Aqui aparece claramente a importância da experiência docente, contribuindo para o enfrentamento de problemas que afetam o professor nos anos iniciais, como a grande preocupação em vencer conteúdos e carga horária em detrimento do acompanhamento e orientação dos alunos em atividade na sala de aula. As "coreografias", neste caso, são repensadas a todo instante, e esta analogia serve para

${ }^{4}$ Professora Ms. da Universidade Federal de Santa Maria, responsável pelo Ateliê de Serigrafia do Curso de Artes Visuais; Coordenadora do Curso em nível de Especialização "Design para Estamparia". Atuante há mais de 20 anos na instituição.

${ }^{5}$ Foram sugeridos para a realização das observações, alguns indicadores, tais como: (i) perfil docente, (ii) perfil discente, (iii) interatividade, (iv) gestão e organização do trabalho pedagógico, (v) métodos, técnicas e estratégias de ensino, (vi) ambiente físico. Todos estes itens possuem subitens, contudo, nem todos se apresentam nos contextos observados, de modo que este texto seguiu um roteiro de acordo com aquilo que foi encontrado com maior relevância. 
compreender que em áreas como essa, alguns alunos estão num ritmo, outros alunos noutro, sem que isto signifique algo negativo, pois todos compartilham do mesmo ambiente, e sem deixar de estarem juntos na tarefa de aprender uns com os outros.

Nesse aspecto, a turma observada apresentou aspectos bastante positivos, pois quanto ao indicador "perfil discente", tanto a interação entre os pares quanto com a professora apontou para a troca de ideias, apoio mútuo e boa comunicação, o que dificultou, por outro lado, a isenção de participação durante as observações por mim realizadas, pois o convite à participação era inevitável, como mais um "ator" no processo.

Outra questão que surgiu nesse contexto de observação foi com relação à "metodologia de ensino e suas estratégias". Em se tratando de uma área criativa, a produção do discente precisa ser acompanhada caso a caso, o que pode ser contornado através de um diálogo para com o grupo (estratégia), pois as dúvidas podem, em alguns momentos, serem compartilhadas, bem como a utilização da própria produção que está sendo concebida como "recurso didático" para a discussão, mesmo que sendo para colocar em destaque orientações gerais, como o uso de equipamentos, a preparação de tintas, o uso da mesa de impressão serigráfica, as etapas de impressão propriamente ditas.

Essas observações levaram também para a reflexão de um dos aspectos principais presentes nesse texto, que é o real impacto das atitudes docentes em sala de aula frente ao aprendizado dos alunos. Um dos aspectos levantados, com relação ao "perfil docente" encontra ressonância na "preocupação com a aprendizagem", que é algo bastante delicado nessa área. O que é aprender em artes? O que está em jogo? É possível interferir nos processos criativos? Devo julgar os resultados estético-formais? Assim, devido às especificidades próprias da área, percebe-se que aqui se insere a "prática artística", que no entender dos docentes, e sobretudo da professora Lusa, é cíclica, ou seja, além de práxis, necessita ao mesmo tempo de uma reflexão teórica de ambas as partes, professor e aluno, para acontecer.

Presenciar situações desse tipo foi de grande relevância para compreender as especificidades da docência em cada campo, e foram inúmeras as vezes em que pesaram, na orientação dos alunos, a necessidade de apenas "sugerir" e "orientar", ao invés de indicar a solução, como ocorre em áreas exatas. Acalmar os alunos na busca de soluções para os "erros" técnicos fez parte da definição de quais os aspectos que o professor poderia interferir (a limpeza e o trato com as telas, a escolha do tecido mais 
apropriado para a impressão e o recebimento de calor na secagem da tinta, a resolução de problemas de desencaixe de impressão) e quais não poderia, no sentido de opinar de maneira definitiva sobre as decisões discentes (a cor escolhida, a estética do projeto, a temática e a teoria adotada, por exemplo).

Essas questões revelam a relação que existe entre a identidade do artista que se torna professor-artista, conforme lembra Almeida (2009), pois muito daquilo que influencia a práxis docente tem a ver com a visão do artista que também existe no professor, que se reflete na pergunta: "o profissional de artes plásticas e de educação, o que ensina?" O campo em questão, segundo a autora, tem passado por diversos dilemas com relação ao ensino das artes visuais plásticas.

Refletir sobre a própria prática faz com que o profissional reveja, atualize, redefina suas atitudes ao ensinar. Isto é o que se observa nos contextos reais de ensino, que podem resultar ou não dessa atitude, contribuindo em certa medida para a formação dos alunos, como, por exemplo, não somente com a formação técnica e estética, mas com a formação humana.

\section{Considerações finais}

Das reflexões desenvolvidas, acredita-se que ser "coreógrafo" ou "ator" são posições intimamente relacionadas, pois o estudante também colabora para o desenho didático, considerando o professor aberto à participação, o que modifica também o docente e seu modo de trabalhar.

Percebe-se que essa ideia pode ser estendida, nos seus aspectos positivos, para os distintos espaços escolares, mas é no espaço universitário que estas questões têm ganhado fôlego, pois é um espaço privilegiado de pesquisa e reflexão. A literatura mostra que este cenário é um lugar de atores que podem e devem seguir bons roteiros para a aprendizagem.

É preciso salientar, como uma das principais questões levantadas pelo viés da aprendizagem, a inserção do estudante no centro, ou seja, é da competência do professor preocupar-se com a aprendizagem de qualidade. Para isso, acredita-se, ao fazer este levantamento bibliográfico e de observação real de ambiente áulico, que do ponto de vista do estudante, as estratégias didáticas devem ocupar outro papel nos planos de ensino, sob pena de que os encaminhamentos docentes na sala de aula pensem as 
"coreografias didáticas" apenas como um quesito organizacional da implementação de um roteiro.

Em um cenário de novos contextos educacionais, essa questão parece premente e um desafio aos professores da atualidade, que precisam lidar com o lugar do estudante como ator e protagonista na situação de ensino que é também de aprendizagem.

\section{REFERENCIAS}

ALMEIDA, Célia Maria de Castro. Ser artista, ser professor: razões e paixões do ofício. São Paulo: Ed. UNESP, 2009.

GADOTTI, Moacir. História das Ideias Pedagógicas. São Paulo: Ed. Ática, 1995.

MACIEL, Adriana Moreira da Rocha. Compreendendo a gestão e organização do trabalho pedagógico no ensino superior. UFSM, 2010.

PADILHA; CAVALCANTE \& ABRANCHES. Ensinagem na docência online: um olhar à luz das coreografias didáticas. Paper, UFPE.

RIOS, Terezinha A. A dimensão ética da aula ou o que nós fazemos com eles. In: Aula: gênese, dimensões, princípios e práticas. São Paulo: Ed. Papirus, 2008.

ZABALZA, M. A. Uma nova didáctica para o ensino universitário. Sessão solene do 95 ${ }^{\circ}$ aniversário da Universidade do Porto. Porto: Universidade do Porto, 2006.

\section{Como referenciar este artigo}

MIRANDA, Vivian Castro de; VEIGA, Adriana Moreira da Rocha. Coreografias didáticas: reflexões acerca dos encaminhamentos docentes em sala de aula para o ensino-aprendizagem nas artes visuais. Revista Ibero-Americana de Estudos em Educação, Araraquara/SP, v. 11, n. 3, p.1343-1351, 2016. Disponível em: <https://dx.doi.org/10.21723/riaee.v11.v3.6013>. E-ISSN: 1982-5587.

Submetido em: 19/06/2013

Aprovação Final em: 28/07/2013 